\title{
Carbon cycling in soil
}

Carol A Johnston ${ }^{1}$, Peter Groffman ${ }^{2}$, David D Breshears ${ }^{3}$, Zoe G Cardon ${ }^{4}$, William Currie ${ }^{5}$, William Emanuel ${ }^{6}$, Julia Gaudinski ${ }^{7}$, Robert B Jackson ${ }^{8}$, Kate Lajtha ${ }^{9}$, Knute Nadelhoffer ${ }^{5}$, David Nelson Jr ${ }^{10}$, W Mac Post ${ }^{11}$, Greg Retallack ${ }^{12}$, and Lucian Wielopolski ${ }^{13}$

As yet, nobody knows what effects climate change will have on soil carbon reserves, or how those changes will affect the global carbon cycle. Soils are the primary terrestrial repository for carbon, so minor changes in the balance between belowground carbon storage and release could have major impacts on greenhouse gases. Soil fauna, roots, fungi, and microbes interact with mineral and organic matter to process soil carbon. Studies have been hampered by the difficulty of observing processes beneath the earth's surface, but advances in science and technology are improving our ability to understand belowground ecosystems.

$S^{o}$ ils contain a huge and dynamic pool of carbon (C), that is a critical regulator of the global carbon budget. As the repository for more than three-fourths of the earth's terrestrial C, soils store 4.5 times the amount of $\mathrm{C}$ contained in vegetation (Lal 2004). Small changes in the processes governing soil $\mathrm{C}$ cycling have the potential to release large amounts of $\mathrm{CO}_{2}$, a greenhouse gas. Because soil gas release is temperature sensitive, global warming will probably create a positive feedback, causing soils to release more greenhouse gases that will further exacerbate the problem. Global climate change may soon provide an opportunity to study the effects of altering soil-atmosphere interactions on a massive scale - or may be doing so already.

Belowground studies pose special challenges because underground structures, organisms, and processes are invisible to humans, who are more used to studying above-

\section{In a nutshell:}

- Vast quantities of carbon in the form of roots and decomposed organic matter are stored in soils

- Physical, chemical, and biological processes within the soil affect the balance between the storage of organic carbon compounds and their release to the atmosphere as $\mathrm{CO}_{2}$ or other greenhouse gases

- New detection methods, large scale experiments, and studies of ancient soils are advancing our understanding of soil carbon cycling processes

${ }^{1}$ South Dakota State University, Brookings, SD 57006 (Carol.Johnston@sdstate.edu); ${ }^{2}$ Institute of Ecosystem Studies, Millbrook, NY; ${ }^{3}$ Los Alamos National Laboratory, Los Alamos, NM; ${ }^{4}$ University of Connecticut, Storrs, CT; ${ }^{5}$ University of Michigan, Ann Arbor, MI; ${ }^{6}$ University of Virginia, Charlottesville, VA; ${ }^{7}$ University of California Santa Cruz, Santa Cruz, CA; ${ }^{8}$ Duke University, Durham, NC; ${ }^{9}$ Oregon State University, Corvallis OR; ${ }^{10}$ Aerodyne Research Inc, Billerica, MA; ${ }^{11}$ Oak Ridge National Laboratory, Oak Ridge, $\mathrm{TN} ;{ }^{12}$ University of Oregon, Eugene, OR; ${ }^{13}$ Brookhaven National Laboratory, Upton, NY ground systems. The types of satellite remote sensors that have advanced aboveground $\mathrm{C}$ studies do not penetrate beyond the soil surface, making remote measurements over large areas impossible. Soil is a dynamic, living system, which is altered by removal from its belowground environment. It is a mix of living and dead plant matter, fungi, macro- and microfauna, plant exudates, and animal waste products, embedded in a matrix of solids, liquids, and gases. When the "black box" of this soil mélange is dissected to study its component parts, its function is altered.

In this paper, we review the issues at the forefront of belowground $\mathrm{C}$ cycling research. Critical societal needs are pushing the science, and the North American Carbon Program Plan (Wofsy and Harriss 2002) has been funded to implement research on measuring and understanding sources and sinks of $\mathrm{CO}_{2}$, methane, and carbon monoxide in the US and its adjacent oceans. Also, the ability of soil to sequester and retain $\mathrm{C}$ is now being brokered via soil $\mathrm{C}$ credits under the US Department of Energy's Voluntary Greenhouse Gas Reporting Program, which was established by section 1605(b) of the Energy Policy Act of 1992. In the sections below, we review some major advances in the field of belowground processes, describe some of the major unanswered questions, and make recommendations for fostering future progress in this important area of research.

This paper is the result of a one-day workshop convened on February 20, 2003, in Arlington, Virginia by Rachael Craig and Knute Nadelhoffer, current and former program officers in the Division of Earth Sciences and Division of Environmental Biology at the National Science Foundation. Additional input occurred at the University of Michigan Biological Station Soil Biology Workshop, held June 16-17, 2004, in Pellston, Michigan.

\section{New study methods}

Systematic study of belowground ecosystems calls for new instruments that will allow in situ, non-destructive analysis of soil. Current non-destructive techniques are still in 
their infancy and require further development and characterization. A variety of instruments are listed below, because it is very unlikely that a single method will resolve all of the outstanding dilemmas posed by this highly diverse field of research.

Inelastic Neutron Scattering (INS) provides the ability to non-invasively measure soil C in situ (Wielopolski et al. $2000,2003)$. INS is based on neutron-induced gamma ray spectroscopy that allows a multi-elemental soil analysis. A single INS analysis of soil takes about 30 minutes and penetrates to a depth of about $20-30 \mathrm{~cm}$ with a footprint of about $30-\mathrm{cm}$ radius for a single detector, thus encompassing a tenth of a cubic meter of soil. INS can be used repeatedly over the same site in sequential measurements to follow changes in the $\mathrm{C}$ inventory, or it can be used to measure the true mean value of an arbitrarily large area that is scanned using a tractor-mounted INS. The target sensitivity of the system is about $0.1 \% \mathrm{C}$ by weight in about 30 minutes counting time.

Laser-induced breakdown spectroscopy is an emerging methodology for making point measurements of soil C, based on atomic emission spectroscopy (Cremers et al. 2001). A laser is focused on a solid sample and forms a microplasma that emits light characteristic of the elemental composition of the sample. The emitted light is collected, spectrally resolved, and analyzed to monitor concentrations of elements by means of their unique spectral signatures. Many measurements can be obtained rapidly and at high spatial resolution. For example, measurements can be taken systematically along the profile of a soil core, yielding a detailed $\mathrm{C}$ profile.

Ground-penetrating radar (GPR) reveals differential transmission, reflectance, and attenuation of the electromagnetic radar signal within soil, with observation depths ranging from less than a meter in clays to 30 meters in some sands (Doolittle et al. 2003). It appears to be suitable for imaging large root systems, identifying interfaces with different electrical permittivity (eg the interface between peat and mineral soil layers), and measuring the distance to subsurface water tables. However, GPR lacks specificity, and caution must be exercised when interpreting the results.

Measurement of the concentrations of greenhouse gases (such as $\mathrm{CO}_{2}$, carbon monoxide, methane, nitric oxide, nitrogen dioxide, and nitrous oxide) in and over soils is needed to improve our understanding of $\mathrm{C}$ release from soils. The recent invention of quantum cascade lasers is driving the development of lower cost, easy-to-use gas monitors which will address these issues (McManus et al. 2002). Applications include direct monitoring of gases in subsoils using underground permeation tubes, and wider use of the eddy covariance method for measuring molecular fluxes to and from soils (Baldocchi 2003). Existing flux measurements can be extended to additional gases, to higher frequency operation (for nighttime measurements) and to more locations (due to ease of use). Use of several flux towers at a given location could help reduce uncertainties associated with horizontal fluxes that cannot be fully addressed with single towers.

Microorganisms can be genetically engineered to provide information about the belowground environment. Called "bioreporters", these bacteria or fungi are designed to reveal the physical or chemical conditions in their soil environment, or their own biological responses to those physical or chemical conditions, by producing an indicator such as green fluorescent or ice nucleation protein (Leveau and Lindow 2002). If the information from such bioreporters can be detected non-destructively and repeatedly, this provides a running commentary of the microbe's activity (eg growth rates) and perception of the environment (eg availability of particular labile $\mathrm{C}$ pools; Bringhurst et al. 2001). Importantly, the information is obtained from the spatial scale perceived and experienced by the microbes. The use of bioreporter organisms is still restricted to manipulated systems.

Another experimental approach under development is the use of miniaturized sensors to provide in situ measurements of pools and processing of particular compounds in soils (Figure 1). These sensors, designed based on prototypes in the biomedical literature (Moussy et al. 1993), rely on immobilized enzymes layered onto a working electrode to produce a substrate-specific signal. The goal is to be able to slip these relatively inexpensive, miniaturized sensors into soil with minimal soil disturbance, in order

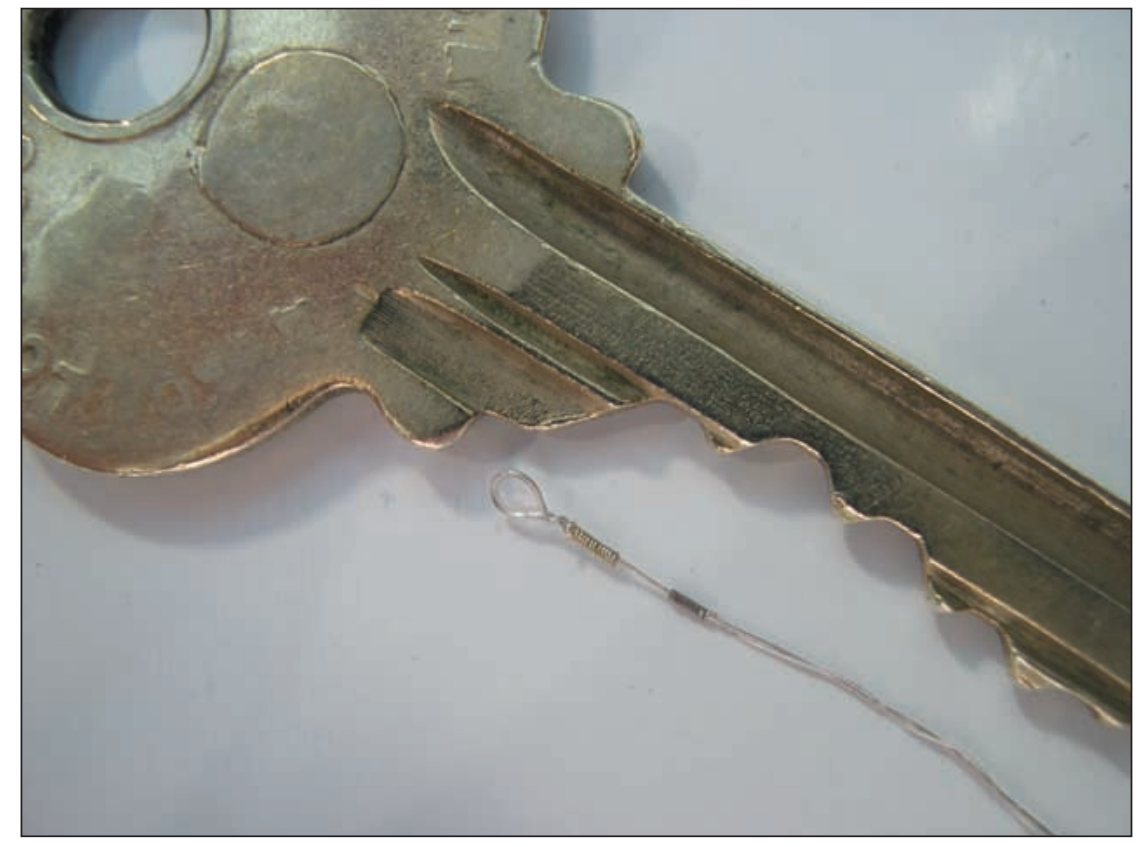

Figure 1. Miniaturized sensor, approximately the size of a small thermocouple, under development for use in soils (Cardon et al. 2003). 


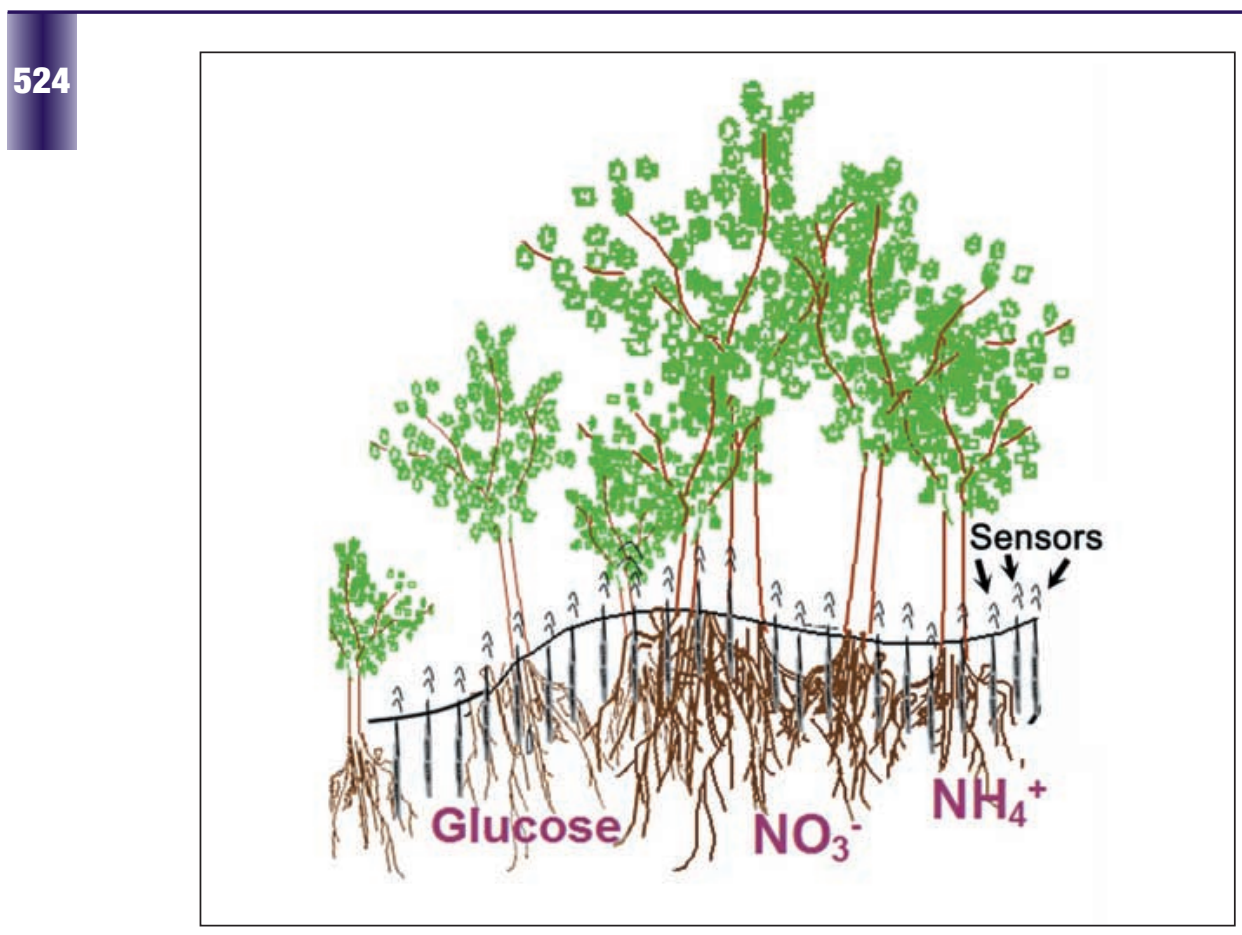

Figure 2. Networks of autonomous soil sensors envisioned for continuous quantification of pools of compounds in situ in the field (eg in the rizosphere).

\section{Large-scale field experiments}

Despite growing knowledge of the short-term dynamics of the fate of plant detritus, or "litter", we know relatively little about the fate of plant litter and its role in determining soil organic matter $(\mathrm{SOM})$ content and nutrient cycling over decades and centuries. To address this gap, a network of long-term, large-scale field experiments have been established to understand controls on SOM formation in forested soils. The Detritus Input and Removal Treatments (DIRT) were inspired by a project started in 1957, at the University of Wisconsin Arboretum (Nielson and Hole 1963), looking at forest and grassland ecosystems. Treatments consist of chronically altering above- and belowground plant inputs to permanent plots and include doubled litter, doubled woody debris, no aboveground litter inputs, no root inputs (prevented by trenches), and no above- or belowground inputs (Figure 3). Treatments were established at Harvard Forest (MA) in 1990, at the Bousson Forest (PA) in 1991, at

to continuously report information about pools of inorganic or organic molecules such as glucose, nitrate, or perhaps suites of organic acids (Figure 2). Linked with taxonomic and genomic information, or with measures of processes (eg gas fluxes), these sensors promise to produce a highly informative match between patterns, processes, and biological diversity in the field. A major, ongoing challenge is developing an outer layer that protects the sensor's immobilized enzyme from microbial attack in soil, while allowing diffusion of the compounds of interest to the enzyme.

New technologies are emerging that allow better characterization and understanding of soil microbes (Clement et al. 1998; Felske et al. 2000; Nunan et al. 2003). These include advanced optical imaging techniques and DNA sequence-based technologies for examining functionality and diversity in the microbial communities. The high throughput techniques being developed in other parts of biotechnology will drive a far greater investigative scope and understanding of soil microbial communities.

Recent advances in ${ }^{13} \mathrm{C}-\mathrm{NMR}$ (nuclear magnetic resonance) and pyrolysis-mass spectrometry offer tremendous potential for understanding the chemical make-up of soil organic matter (Kogel-Knabner 1997). ${ }^{13} \mathrm{C}-\mathrm{NMR}$ spectrometry is a non-destructive measurement of the shift in resonance peak(s) of ${ }^{13} \mathrm{C}$-nuclei, as affected by the nature and configuration of adjacent atoms. The resulting spectrum is divided into general classes related to chemical structure: alkyl, o-alkyl, aromatic, and carbonyl. Because these are non-destructive techniques, multiple NMR experiments can be performed on any one sample. the HJ Andrews Forest (OR) in 1997, and in the Síkftkút Forest (Hungary) in 2001. Although DIRT addresses long-term questions about SOM formation, treatments have also been used to separate sources of respiration (Bowden et al. 1993; Boone et al. 1998) and to determine litter-induced differences in dissolved organic carbon quantity, chemistry, and sorption in mineral soil (Yano et al. in press).

Research in grassland ecosystems has examined the effects of natural and human disturbances on belowground $\mathrm{C}$ cycling, often through the use of long-term studies or a chronosequence of sites. Disturbances investigated include the effects of fire (Knapp et al. 1998; Johnson and Matchett 2003), grazing (Reeder et al. 2004), agriculture (Burke et al. 1995; Izaurralde et al. 2001; Post et al. 2004), and grassland restoration (Jastrow et al. 1998; Baer et al. 2002).

\section{New evidence from old soils}

The morphology, petrography, and stratigraphy of past soil horizons (paleosols) provide insights into relationships between climate and $\mathrm{C}$ accumulation in the geologic past that can be used to infer the current role of soils (Retallack 2002). Carbon consumption and sequestration in modern soils is greater within the fertile soils of the northern hemisphere than in the infertile and ancient soils of the southern hemisphere. For these reasons, temperate forests and grasslands are probably the most important $\mathrm{C}$ sinks, and rainforest, tundra, and swamp soils are less important sinks. These trends can also be seen from micromorphological and $\mathrm{C}$ and nitrogen isotopic studies of paleosols. On geological time 


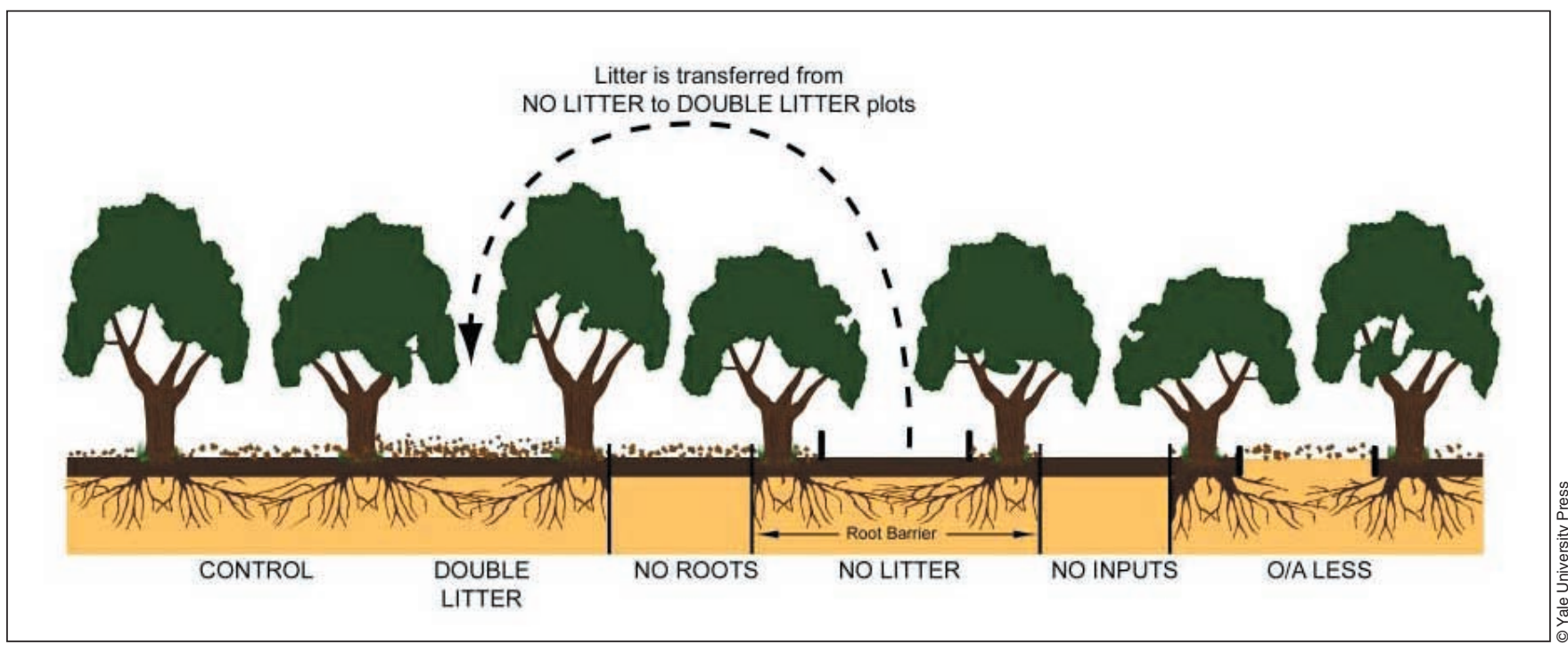

Figure 3. Design of the DIRT experiment (Nadelhoffer et al. 2004)

scales, evolutionary innovations in soil biota (such as termites) have diminished $\mathrm{C}$ sequestration and resulted in greenhouse periods. Conversely, evolutionary innovations in plants, such as the acquisition of lignin and woody tree trunks, have led to increased $\mathrm{C}$ sequestration and long ice ages (Retallack 2001). The concept that plants cool the planet whereas fauna warm it, called the "Proserpina Principle" after the Roman goddess of spring, underscores the fragile balance between storage and release of soil C.

\section{Critical issues and questions}

A belowground science program should improve understanding of fundamental soil processes and the role of soils with regard to global change. In order to quantify $\mathrm{C}$ pools and their dynamics at scales relevant for ecosystem, regional, and global $\mathrm{C}$ budgets, we must understand critical mechanisms that control soil organic matter chemistry, formation, and accumulation, including those relevant to management of soil C.

\section{Bulk density measurement}

Soil is porous and three-dimensional, so measurements of soil bulk density (ie soil mass per unit volume) are essential for extrapolating the $\mathrm{C}$ concentrations of dried, ground samples to $\mathrm{C}$ stocks of whole landscapes and the globe. Existing techniques for measuring soil bulk density are accurate to within only $10-20 \%$ of the true density. This means an uncertainty in global soil $\mathrm{C}$ stocks of 150-400 gigatons of carbon. In order to improve our ability to accurately measure soil $\mathrm{C}$ stocks and fluxes we need to greatly improve our ability to measure soil bulk density, and require all soil $\mathrm{C}$ researchers to measure it. Existing bulk density measurement methods could be improved by linking excavations, especially large excavations with the types of equipment used for below- ground pipeline and utility wire installation, with reconnaissance measures (ie geophysical techniques).

\section{Fine root dynamics}

Accurate calculation of all root-derived fluxes into soil $\mathrm{C}$ pools requires an understanding of some very basic root ecology, such as the cycle of fine root life and death. Improvements are needed in the measurement and modeling of belowground fine root inputs. Fine root data models are quite uniform in their assumption that a fine root population is at steady state (averaged at annual time scales) and that all roots within that population have an equal probability of death. Yet, fine root architecture is immensely complex, and there is a growing body of new evidence showing variation in lifespan as a function of position on the root branching system, root diameter, nitrogen content, and mycorrhizal association. Researchers at the Hubbard Brook LTER observed fine root survivorship using video images taken inside clear plastic tubes inserted into the soil (minirhizotrons) over a 5-year period. Using the minirhizotron record and a parametric model that accounts for different rates of root death, they calculated a mean lifetime for roots of 3.3 years (Tierney and Fahey 2002), much longer than the mean lifetime of less than one year that the same authors published the previous year (Tierney and Fahey 2001). Their change in approach largely came about after considering ${ }^{14} \mathrm{C}$ data that suggested longer lifetimes than one year. It now appears that the age of fine roots may well range from months to decades.

\section{Coevolution of belowground biota}

Roots evolved during the last 400 million years surrounded by communities of soil microbes and soil fauna. Over geologic time scales, biogeochemical 
cycling on Earth was dramatically changed by the evolution of large, deeply-rooted plants during the Devonian (400-350 million years ago). Weathering of silicate rocks much deeper into the surface profile on the planet may have drawn down $\mathrm{CO}_{2}$ concentrations through burial of calcium carbonate in ocean sediments (perhaps cooling Earth's climate). The continuous coevolution of plant roots, soil microbes, and fauna, through their intimate association over evolutionary time, has resulted in the plant $\mathrm{C}$ allocation strategies, root physiological behaviors, root structural properties, root chemistries, and microbial decomposition processes that we focus on today as important in biological, shorter term $\mathrm{C}$ cycling and storage. These processes of ancient $\mathrm{C}$ cycling in soil have left a detailed record in the root traces and burrows, micromorphology, and chemical depth functions of paleosols, which require basic documentation and exploration. Research is needed on the selective pressures that have operated through this biological association to influence soil faunal communities and plant ecophysiological patterns of rhizodeposition.

\section{Role of soil fauna}

Soil fauna may be critical regulators of belowground C dynamics, especially the response to elevated $\mathrm{CO}_{2}$ (Porazinska et al. 2003). As plants are exposed to elevated $\mathrm{CO}_{2}$, they fix more $\mathrm{C}$ from the atmosphere and pump much of it belowground. Bacteria and fungi take up this $\mathrm{C}$, but their growth and activity are strongly affected by faunal grazing. Our understanding of soil microbial and soil faunal diversity, and the biogeochemical processing role of specific taxonomic groups, is currently so rudimentary that it precludes development of a general framework for understanding belowground C dynamics.

While aboveground invasions have received a lot of attention, there have been relatively few studies on the effects of invasive species on belowground ecosystems. Exotic species of earthworms are invading glaciated regions of North America, displacing native species of earthworms and replacing ant-dominated belowground systems (Hendrix and Bohlen 2003). Invasion has the potential to substantially reduce soil $\mathrm{C}$ storage on a regional scale (Bohlen et al. 2004). There is great need to characterize the nature and extent of these invasions, their effects on soil $\mathrm{C}$ dynamics, and their interaction with climate change.

\section{Geographic gaps in knowledge}

Urban and suburban land cover is increasing at a great rate, at the expense of agricultural and forested land. These areas have large amounts of natural and semi-natural soils and vegetation, yet rates of $\mathrm{C}$ cycle processes and storage are very poorly understood.
The soils of wetlands (particularly peatlands) and tundra are carbon rich, and their $\mathrm{C}$ retention is likely to be affected by changes in hydrology as well as temperature under predicted climate-change scenarios. These soils are located primarily in high latitudes that are anticipated to experience the greatest warming. Better information is needed about their spatial distribution, particularly in areas where isolated wetlands are small but contain a large proportion of landscape $\mathrm{C}$ stores.

\section{Extreme events}

Extreme events, such as drought and related fire and erosion, can result in very rapid losses of soil C. High intensity crown fires can volatilize soil $\mathrm{C}$ and trigger high erosion rates that further exacerbate soil C losses. Drought can result in plant mortality that triggers high soil erosion rates, particularly in semiarid ecosystems (Breshears and Allen 2002). Better information is needed on rates of soil C loss associated with fire, erosion, and other extreme events for a variety of ecosystem types.

\section{Recommendations for future progress}

A number of different research approaches are needed for advancing belowground science, including investigator-driven research, coordinated network campaigns, and modeling. Coordinated network campaigns enable multiple resources to be focused on a particular site, leveraging information and simplifying logistics. Investigator-initiated research promotes individual innovation and often results in breakthroughs that would be difficult under the constraints of a coordinated network campaign. Environmental observatories for belowground processes that already exist at some research sites (eg some LTER and FACE sites), could be added to other well-characterized research sites (eg AmeriFlux sites), and could be established in new locations to target gaps in national coverage (eg NEON sites). Archiving of key data and samples is needed to provide a long-term perspective. In addition, a data archive and retrieval system is needed for key soil measurements. For example, a long-term record of subsurface temperatures in a warming world might be very valuable in the future, because decomposition is so sensitive to temperature.

New belowground research efforts must address scaling issues from the outset. Our knowledge of belowground conditions is based almost exclusively on point measurements. Soil temperature probes, minirhizotron tubes, and soil cores convey information about a single point in the earth, and many such measurements are needed to characterize large areas. Non-destructive techniques have the potential to provide information about a larger swath of soil, particularly if the device can be towed over the ground surface, but the problem 
of data interpolation between swaths still exists. The spatial variability of soil properties must be explored using refined statistical techniques: geostatistical techniques, decision trees, and regression analyses between digital elevation models (and satellite data) and soil property data. Scaling techniques are also needed to analyze temporal variation, particularly to integrate and quantify fluxes during periods of rapid change (eg over hours and days).

Modeling has been, and should continue to be, an important tool in belowground research. Major advances in the understanding of global $\mathrm{C}$ dynamics resulted from the International Biological Program (IBP), in which data on primary production were collected at sites around the world. These data enabled authors of the CENTURY model (Parton et al. 1978) to develop and verify a model of ecosystem $\mathrm{C}$ dynamics that is still in widespread use more than two decades later (Parton et al. 1998). A new generation of models is now needed for soil $\mathrm{C}$ cycling and biogeochemistry. Modeling efforts and field studies should be linked closely, allowing more relevant progress to be made in concert on both fronts. Models should be developed with the goal of understanding and predicting key dynamics of soil $\mathrm{C}$ in relation to ecosystem processes and socioeconomic drivers under scenarios of global and regional change. Models of past $\mathrm{C}$ cycling and paleoclimates also need to be better informed of past soil conditions than the current generation of such models.

Given the breadth of expertise needed to advance belowground science, a research program should promote disciplinary integration. Ecologists and geochemists should be linked with chemists and technologists. Studies of modern C cycling should be linked to studies of past perturbations found in paleosols and other sources. Human and socioeconomic science is needed to develop new approaches to $\mathrm{C}$ management. Only by applying knowledge and innovations from multiple disciplines can we open the black box of the soil for a greater mechanistic and predictive understanding of soil $\mathrm{C}$ dynamics.

\section{Acknowledgments}

We thank R Craig of the National Science Foundation for support of the workshop in which we were participants.

\section{References}

Baer SG, Kitchen DJ, Blair JM, and Rice CW. 2002. Changes in ecosystem structure and function along a chronosequence of restored grasslands. Ecol Appl 12: 1688-01.

Baldocchi DD. 2003. Assessing the eddy covariance technique for evaluating carbon dioxide exchange rates of ecosystems: past, present and future. Global Change Biol 9: 479-92.

Bohlen PJ, Groffman PM, Fahey TJ, and Fisk MC. 2004. Ecosystem consequences of exotic earthworm invasion of north temperate forests. Ecosystems 7: 1-13.
Boone RD, Nadelhoffer KJ, Canary JD, and Kaye JP. 1998. Roots exert a strong influence on the temperature sensitivity of soil respiration. Nature 396: 570-72.

Bowden RD, Nadelhoffer KJ, Boone RD, et al. 1993. Contributions of aboveground litter, belowground litter, and root respiration to total soil respiration in a temperate mixed hardwood forest. Can J Forest Res 23: 1402-07.

Breshears DD and Allen CD. 2002. The importance of rapid, disturbance-induced losses in carbon management and sequestration. Global Ecol Biogeogr 11: 1-5.

Bringhurst RM, Cardon ZG, and Gage DJ. 2001. Galactosides in the rhizosphere: utilization by Sinorhizobium meliloti and development of a biosensor. Proc Natl Acad Sci USA 98: 4540-45.

Burke IC, Lauenroth WK, and Coffin DP.1995. Soil organic-matter recovery in semiarid grasslands: implications for the conservation reserve program. Ecol Appl 5: 793-801.

Cardon Z, Tyser D, and Moussy F. 2003. A new, nondestructive window into dynamics of sugar concentrations around plant roots in the field. Abstracts, 88th Annual Meeting of the Ecological Society of America; 2003 Aug 3-8; Savannah, GA. http://abstracts.co.allenpress.com/pweb/esa2003/document/?ID $=27252$. Viewed 4 November 2004 .

Clement BG, Kehl LE, De Bord KL, and Kitts CL. 1998. Terminal restriction fragment patterns (TRFPs), a rapid, PCR-based method for the comparison of complex bacterial communities. J Microbiol Meth 31: 135-42.

Cremers DA, Ebinger MH, Breshears DD, et al. 2001. Measuring total soil carbon with laser-induced breakdown spectroscopy (LIBS). J Environ Qual 30: 2202-06.

Doolittle JA, Minzenmayer FE, Waltman SW, and Benham EC. 2003. Ground penetrating radar soil suitability maps. J Environ Eng Geo 8: 49-56.

Felske A, Wolterink F, Van Lis R, et al. 2000. Response of a soil bacterial community to grassland succession as monitored by $16 \mathrm{~S}$ rRNA levels of the predominant ribotypes. Appl Environ Microb 66: 3998-4003.

Hendrix PF and Bohlen PJ. 2002. Exotic earthworm invasions in North America: ecological and policy implications. BioScience 52: 801-11.

Izaurralde RC, McGill WB, Robertson JA, et al. 2001. Carbon balance of the Breton classical plots over half a century. Soil Sci Soc Am J 65: 431-41.

Jastrow JD, Miller RM, and Lussenhop J. 1998. Contributions of interacting biological mechanisms to soil aggregate stabilization in restored prairie. Soil Biol Biochem 30: 905-16.

Johnson LC and Matchett JR. 2001. Fire and grazing regulate belowground processes in tallgrass prairie. Ecology 82:3377-89.

Knapp AK, Conard SL, and Blair JM. 1998. Determinants of soil $\mathrm{CO}_{2}$ flux from a sub-humid grassland: effect of fire and fire history. Ecol Appl 8: 760-70.

Kogel-Knabner I. $1997 .{ }^{13} \mathrm{C}$ and ${ }^{15} \mathrm{~N}$ NMR spectroscopy as a tool in soil organic matter studies. Geoderma 80: 243-70.

Lal R. 2004. Soil carbon sequestration impacts on global climate change and food security. Science 304: 1623-27.

Leveau JHJ and Lindow SE. 2002. Bioreporters in microbial ecology Curr Opin Microbiol 5: 259-65.

McManus JB, Nelson DD, Shorter JH, et al. 2002. Quantum cascade lasers for open- and closed-path measurement of atmospheric trace gases. In: Fried A (Ed). Diode lasers and applications in atmospheric sensing. P Soc Photo-opt Inst 4817: 22-33.

Moussy F, Harrison DJ, O'Brien DW, and Rajotte RV. 1993. Performance of subcutaneously implanted needle-type glucose sensors employing a novel tri-layer coating. Anal Chem 65: 2072-77.

Nadelhoffer KJ, Boone RD, Bowden RD, et al. 2004. The DIRT experiment: litter and root influences on forest soil organic matter stocks and function. In: Foster D and Aber J (Eds). Forests in time: the environmental consequences of 1000 years of change in New England. New Haven, CT: Yale University Press. 
Neilson GA and Hole FD. 1963. A study of the natural processes of incorporation of organic matter into soil in the University of Wisconsin Arboretum. Wisc Acad Rev 50: 231-27.

Nunan N, Wu K, Young IA, et al. 2003. Spatial distribution of bacterial communities and their relationships with the microarchitecture of soil. FEMS Microbiol Ecol 44: 203-15.

Parton WJ, Singh JS, and Coleman DC. 1978. A model of production and turnover of roots in a shortgrass prairie. J Appl Ecol 15: $515-24$.

Parton WJ, Hartman M, Ojima D, and Schimel D. 1998. DAYCENT and its land surface submodel: description and testing. Global Planet Change 19: 35-48.

Porazinska DL, Bardgett RD, Blaauw MB, et al. 2003. Relationships at the aboveground-belowground interface: plants, soil biota, and soil processes. Ecol Monogr 73: 377-95.

Post WM, Izaurralde RC, Jastrow JD, et al. 2004. Enhancement of carbon sequestration in U.S. soils. BioScience 54: 895-908.

Reeder JD, Schuman GE, Morgan JA, and LeCain DR. 2004. Response of organic and inorganic carbon and nitrogen stocks to long-term grazing of the shortgrass steppe. Environ Manage 33: 485-95.

Retallack GJ. 2001. Cenozoic expansion of grasslands and climatic cooling. J Geol 109: 407-26.
Retallack GJ. 2002. Carbon dioxide and climate over the past 300 Myr. Philos T Roy Soc A 360: 659-73.

Tierney GL and Fahey TJ. 2001. Evaluating minirhizotron estimates of fine root longevity and production in the forest floor of a temperate broadleaf forest. Plant Soil 229: 167-76.

Tierney GL and Fahey TJ. 2002. Fine root turnover in a northern hardwood forest: a direct comparison of the radiocarbon and minirhizotron methods. Can J Forest Res 32: 1692-97.

Wielopolski L, Orion I, Hendrey G, and Roger H. 2000. Soil carbon measurements using inelastic neutron scattering. IEEE T Nucl Sci 47: 914-17.

Wielopolski L, Mitra S, Hendrey G, et al. 2003. Nondestructive in situ soil carbon analysis: principle and results. Proceedings of the Second Conference on Carbon Sequestration. www.carbonsq.com/pdf/posters/TII6.pdf. Viewed 17 May 2004.

Wofsy SC and Harriss RC. 2002. North American Carbon Plan (NACP). Report of the NACP Committee of the US Interagency Carbon Cycle Science Program. Washington DC: US Global Change Research Program.

Yano Y, Lajtha K, Sollins P, and Caldwell BA. Chemistry and dynamics of dissolved organic matter in a temperate coniferous forest on andic soils: effects of litter quality. Ecosystems. In press. 